\title{
CORRECTION
}

\section{Correction to: Noninvasive Intracranial Pressure Assessment in Acute Liver Failure}

\author{
Venkatakrishna Rajajee ${ }^{1,2^{*}}$, Craig A. Williamson ${ }^{1,2}$, Robert J. Fontana ${ }^{3}$, Anthony J. Courey ${ }^{4}$ and Parag G. Patil ${ }^{1}$
}

๑ 2018 Springer Science+Business Media, LLC, part of Springer Nature and Neurocritical Care Society

\section{Correction to: Neurocrit Care}

https://doi.org/10.1007/s12028-018-0540-x

The authors note that the number 14 was inadvertently omitted from the formula listed on page 5 of the article. It currently reads

$$
\mathrm{CPPe}=\mathrm{MAP} *(\mathrm{EDV} / \mathrm{TAPV})
$$

The correct formula is

$$
\mathrm{CPPe}=\mathrm{MAP} *(\mathrm{EDV} / \mathrm{TAPV})+14
$$

The number 14 was inadvertently cut out and the oversight was not noticed during the review or the proof process.

The authors would also like to add a reference:

Soldatos T, Karakitsos D, Chatzimichail K, Papathanasiou M, Gouliamos A, Karabinis A. Optic nerve sonography in the diagnostic evaluation of adult brain injury. Crit Care. 2008;12(3):R67. doi: 10.1186/cc6897. Epub 2008 May 13.

Reference would be cited along with the mention of reference 16 in the Methods section on page 5 of the article.

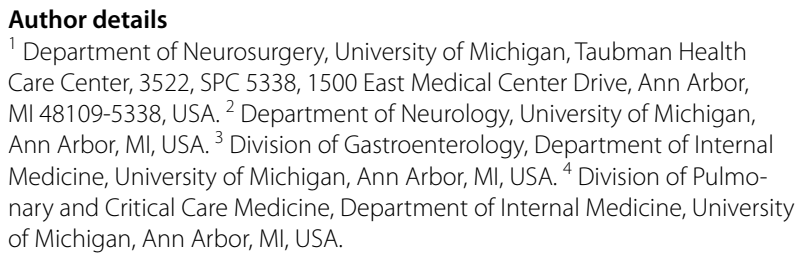
Care Center, 3522, SPC 5338, 1500 East Medical Center Drive, Ann Arbor, MI 48109-5338, USA. ${ }^{2}$ Department of Neurology, University of Michigan, Ann Arbor, MI, USA. ${ }^{3}$ Division of Gastroenterology, Department of Internal Medicine, University of Michigan, Ann Arbor, MI, USA. ${ }^{4}$ Division of Pulmonary and Critical Care Medicine, Department of Internal Medicine, University of Michigan, Ann Arbor, MI, USA.

Published online: 30 October 2018 